\title{
TELAAH KRITIS ETIKA LINGKUNGAN LYNN WHITE
}

\author{
Yohanes Hasiholan Tampubolon \\ STTT SAPPI Ciranjang \\ yohanes tampubolon@sttsappi.ac.id
}

\begin{abstract}
Lynn White was known for her criticism of Christianity in 1967 in her thesis "The Historical Roots of Our Ecologic Crisis". In addition to these criticisms, White also made constructive contributions through his views on environmental ethics. White rejects anthropocentric and instrumentalist ethics. White proposed an ethic of compassion for nature rooted in his notion of a "spiritual democracy of all God's creatures." This ethical model is offered as a means to change attitudes and behaviors to overcome the problem of environmental degradation. The ethical model is then adapted and criticized by scholars. However, in the midst of environmental degradation requires urgent responses, we need an adaptive ethics that can encourage all people to be involved in the transformation of life, be it the transformation of individual world views, practical applications and structure of social life.
\end{abstract}

Keywords: environmental ethics, Christianity, environmental degradation, religion, Lynn White.

\section{ABSTRAK}

Lynn White dikenal melalui kritiknya terhadap agama Kristen dalam artikelnya The Historical Roots of Our Ecologic Crisis tahun 1967. Selain kritik tersebut, White juga memberikan kontribusi konstruktif melalui pandangannya mengenai etika lingkungan. White menolak etika antroposentris dan instrumentalis, ia menganjurkan etika demokrasi spiritual semua makhluk Tuhan. Model etika ini ditawarkan sebagai sarana untuk mengubah sikap dan perilaku untuk mengatasi masalah kerusakan lingkungan. Model etika tersebut kemudian diadaptasi dan dikritisi oleh para sarjana. Namun, di tengah kerusakan lingkungan yang semakin membutuhkan respon mendesak, diperlukan etika yang adaptif yang yang dapat mendorong semua umat untuk terlibat dalam transformasi kehidupan, baik itu transformasi pandangan dunia individual, dalam aplikasi praktis keeharian hingga transformasi struktur kehidupan bermasyarakat.

Kata-kata kunci: etika lingkungan, kristen, kerusakan lingkungan, agama, Lynn White. 


\section{PENDAHULUAN}

Tidak dapat disangkali bahwa bumi saat ini sedang dalam masa puncak kerusakan. Manusia menjadi aktor dalam rusaknya keanekaragaman hayati, kenaikan permukaan laut, meningkatnya konsentrasi gas karbon dioksida, dan sebagainya. Rusaknya keanekaragaman hayati akibat perubahan iklim dan berdampak pada punahnya beragam jenis spesies, penyusutan sumber daya genetik dan perubahan fenologi. Kenaikan permukaan laut diakibatkan mencairnya lapisan es di Arktik sejak abad 19 dan intensitas mencair meningkat di abad 20 hingga sekarang (Nur 2019). Meningkatnya konsentrasi gas karbon dioksida disebabkan oleh banyaknya pembakaran bahan bakar minyak dan bahan bakar lainnya di sisi lain tumbuh-tumbuhan dan laut tidak mampu untuk menyerapnya.

Perubahan iklim yang terjadi saat ini mendorong, memperburuk dan memperumit masalah lingkungan. Berbagai penelitian telah meyakinkan bahwa perubahan iklim adalah nyata, namun, penyelesaian untuk mengatasi permasalan tersebut sangat kompleks.

Di tengah berbagai kenyataan kerusakan bumi saat ini, pada tahun 1967, Lynn White menerbitkan tulisan yang berjudul The Historical Roots of Our Ecologic Crisis. Tulisan tersebut bisa dikatakan kontroversional karena ia berpendapat bahwa pengaruh agama Kristen dalam abad pertengahan merupakan akar penyebab kerusakan lingkungan di abad ke-20. Tidak hanya bumi yang sedang menghadapi krisis lingkungan, namun etika Kristenpun sedang mengalami krisis.

Setelah tulisan tersebut beredar, berbagai tanggapanpun bermunculan. Hingga saat ini hampir pasti ditemukan referensi dari tulisan Lynn White tersebut di buku-buku etika Kristen yang membahas mengenai lingkungan. Namun, di sisi lainnya, Lynn White juga menerbitkan tulisan mengenai etika Kristen yang mendukung pelestarian keutuhan ciptaan. Tulisan tersebut sering diabaikan dibandingkan tulisan kontroversionalnya di tahun 1967.

Artikel ini akan dimulai dengan menjelaskan signifikansi pemikiran Lynn White, melihat keresahan Lynn White terhadap etika lingkungan Kristen yang kemudian melahirkan etika demokrasi spiritual seluruh ciptaan dan diakhiri dengan telaah kritis etika lingkungan Lynn White setelah empat dekade berlalu. 


\section{METODE PENELITIAN}

Artikel ini menggunanakan metode penelitian kepustakaan (library research). Metode ini akan dilakukan dengan teknik pengumpulan data melalui penelaahan terhadap buku, jurnal, catatan, sumber-sumber daring serta berbagai laporan yang berkaitan dengan masalah yang ingin dipecahkan. Melalui metode ini penulis akan melakukan elaborasi mengenai signifikansi etika lingkungan Lynn White, pandangannya terhadap etika kristen dan alternatif etika lingkungan yang ditawarkannya. Kemudian proses penelitian akan dilakukan menganalisis dan mengkritisi etika lingkungan Lynn berdasarkan pengamatan penulis dari data-data yang dikumpulkan sesudah beberapa dekade pandangan Lynn White.

\section{SIGNIFIKANSI LYNN WHITE}

Eksploitasi terhadap alam semakin masif sejak revolusi industri yang ditandai dengan hadirnya pabrik-pabrik dan berkembangnya teknologi secara cepat. Di tengah kerusakan alam yang semakin masif, manusiapun mulai memikirkan mengenai etika lingkungan. Tulisan Rachel Carson yang berjudul Silent Spring pada tahun 1962 mengawali literatur lainnya. Pada periode 1960-an ada juga terbit tulisan dari Garret Hardin yang berjudul The Tragedy of the Commons (1968) dan Paul Ehrlich yang berjudul The Population Bomb (1968). Kedua tulisan tersebut melihat stimulus degradasi lingkungan berasal dari dorongan ekonomi dan pertumbuhan populasi manusia. Tulisan Lynn White memiliki keistimewaan dibandingkan tulisan mengenai isu lingkungan lainnya di periode 1960-an. Lynn White lebih memerhatikan persoalan ide-ide dan nilai-nilai manusia yang mendasari kerusakan lingkungan. Wacana pada umumnya di masa itu lebih melihat penyebab material dari kerusakan lingkungan, seperti dampak polusi terhadap kesehatan manusia, masalah ekonomi dan teknologi hingga persaingan politis memperebutkan sumber daya alam. ${ }^{1}$

${ }^{1}$ Setidaknya ada tiga kelompok pendekatan dalam wacana etika lingkungan, yaitu pendekatan instrumental, pendekatan aksiologikal dan pendekatan antropoligikal. Pendekatan instrumental memiliki pendekatan antroposentris, yang mementingkan kepentingan manusia itu dalam melakukan pengelolaan dan proteksi terhadap alam. Pendekatan aksiologikal sebaliknya, pendekatan ini mengasumsikan bahwa alam memiliki nilai-nilai sendiri sehingga manusia harus menyelamatkan dan melindungi nilai yang ada dalam setiap komponen alam tersebut. Ketiga, pendekatan antropologi yang melihat manusia memiliki kedekatan hubungan dengan alam apabila manusia "merasakan" dan memahami nilai-nilai instrinsik yang dikandung oleh komponen alam. Dari ketiga 
Hadirnya tulisan White di tahun 1967 memberikan wacana segar dan kontroversional mengenai etika lingkungan. Berbeda dengan Lynn White, wacana lainnya cenderung menggunakan pendekatan instrumental dalam melihat persoalan lingkungan. Menurut White, ide-ide dan nilai-nilai memiliki peranan besar dalam degradasi lingkungan di abad ke-20. Kekristenan kemudian dituduh menjadi agama yang paling bertanggung jawab atas apa yang terjadi saat ini. Krisis lingkungan yang lebih banyak di lihat karena perkembangan sains dan teknologi dibalikkan oleh White yang mengidentifikasi ide-ide dan nilai-nilai agama yang menjadi akar persoalan. Jika ingin memperbaiki persoalan tersebut, maka perlu ada set nilai-nilai dasar baru yang diterima masyarakat (White 1967:1207). Kontroversi dan perdebatanpun terus-menerus terjadi di tengah hadirnya wacana baru tersebut.

Tulisan White tersebut adalah awal dari upaya memahami nilai-nilai dan ide-ide yang berdampak pada perilaku dan sikap terhadap alam. Tidak berlebihan jika dikatakan bahwa Lynn White merupakan "episenter" etika lingkungan yang ada pada saat itu. John Callicott, seorang filsuf Amerika dan berperan penting dalam mengembangkan filsafat lingkungan, menggambarkan The Historical Roots of Our Ecologic Crisis sebagai seminal paper dalam etika lingkungan (Callicott 1999:40). Teolog Kristen yang mengajarkan mengenai penatalayan ciptaan Allah dengan baik seperti James Barr, Francis Schaeffer, dsb., menurut Callicott diprovokasi oleh White (Callicott 1999:41). Callicott setuju dengan klaim bahwa apa yang kita lakukan tergantung pada apa yang kita pikirkan dan jika kita ingin mengubah apa yang kita lakukan terhadap lingkungan, tentunya kita harus mulai dengan mengubah apa yang kita pikirkan tentang lingkungan (Callicott 1999:40).

Menurut ahli etika lingkungan, Willis Jenkins, tulisan White sangat berpengaruh dalam membentuk etika agama memahami masalah lingkungan (Jenkins 2009:283). Menurutnya, Lynn White menarik kontroversi dengan berpendapat bahwa akar krisis ekologis terletak pada kosmologi agama, khususnya dalam pandangan antroposentrisme dan instrumentalis dari kekristenan barat, namun di sisi lain, metode Lynn White dalam menghubungkan implikasi moral kosmologi agama dengan masalah lingkungan telah membantu mengembangkan bidang akademik etika lingkungan dan agama (Jenkins 2009:283). Dengan demikian, karya White memiliki dampak yang luas, tidak hanya bagi etika lingkungan tetapi juga etika agama.

pendekatan tersebut, pendekatan instrumental adalah pendekan yang digunakan oleh penulis di era 1960-an selain Lynn White (Marfa 2016:23-24). 
Pemikiran White berdampak penting dalam sejarah filsafat lingkungan dan etika lingkungan Kristen. Di periode kehidupannya lebih banyak ahli menyoroti penyebab material dari kerusakan lingkungan (Carson dan Ehrlich), sedangkan White melihat akar kerusakan lingkungan adalah ide-ide dan nilai-nilai kosmologi Kristen yang mendorong perilaku eksploitatif. Namun, White tidak sekadar mengkritisi kekristenan, ia juga mengembangkan etika "hijau" yang didasari pada ajaran kristen.

\section{ETIKA KRISTEN DALAM KRISIS}

White melihat bahwa etika Kristen berada dalam keadaan krisis yang bahkan belum pernah terjadi sebelumnya dalam sejarah tradisi Kristen. Lynn White mengeksplorasi nilai-nilai Kristiani yang dituliskan dalam The Ecumenical Review pada tahun 1978, berjudul The Future of Compassion, White menjelaskan bahwa saat ini etika Kristen telah usang, bahkan dalam zaman ini menjadi destruktif sehingga perlu arah yang baru demi masa depan yang lebih baik (White 1978:104-5).

White melihat konsumerisme telah mendominasi budaya saat ini dan menghancurkan "kerohanian" kekristenan, hal itu akan berdampak pada krisis kemudian akan menghancurkan secara fisik kecuali manusia mengubah nilai-nilai dominan yang ada saat ini yaitu nilai-nilai dominan destruktif yang berasal dari kekristenan. Di sisi lainnya kekristenan gagal melihat konteks perubahan zaman dan mempertimbangkan perubahan moral untuk berbelas kasihan kepada para budak, perempuan dan hewan (White 1978:100-104). Keadaan yang demikian dianggap merupakan kegagalan etika Kristen apalagi ditambah pertimbangan untuk peduli terhadap lingkungan.

White melihat hal-hal praktis yang dilakukan untuk mencegah kerusakan lingkungan tampak terlalu parsial, paliatif, negatif: seperti melarang bom, merobohkan papan reklame, memberikan alat kontrasepsi atau kembali ke masa lalu yang romantis (White 1967:1204). White tidak menjelaskan secara spesifik halhal praktis apa yang harus dilakukan, namun ia mengajak untuk mengklarifikasi pemikiran dengan melihat kembali kepada sejarah, pada presuposisi yang mendasari teknologi dan sains, mengeksplorasi sisi teologis dan etis lebih lanjut (White 1967:1204). Mengatasi permasalahan lingkungan perlu dengan cara memikirkan kembali aksioma yang mendasari kehidupan saat ini.

Matthew Riley melihat tulisan White mencerminkan gagasan Max Weber yang mana pendekatan penyelesaian krisis ekologis perlu didahului dengan 
pemeriksaan fondasi Kristen yang dianggap mendukung perusakan lingkungan (Riley 2017:67). Gagasan White tersebut tertulis demikian:

"I personally doubt that disastrous ecologic backlash can be avoided simply by applying to our problems more science and more technology. Our science and technology have grown out of Christian attitudes toward man's relation to nature which are almost universally beld not only by Christians and neo-Christians but also by those who fondly regard them-selves as post-Christians. Despite Copernicus, all the cosmos rotates around our little globe. Despite Darwin, we are not, in our hearts, part of the natural process. We are superior to nature, contemptuous of it, willing to use it for our slightest whim." (White 1967:1206)

Tantangan bagi kekristenan adalah melampaui etika instrumentalis yang berpusat pada manusia dan mulai memikirkan set pemikiran yang peduli pada keutuhan ciptaan.

Etika instumentalis memandang bahwa manusia adalah satu-satunya yang memiliki nilai instrinsik. Pandangan instrumentalis tentang alam memisahkan secara ontologis antara manusia dan alam, seperti dalam tulisan-tulisan John Locke dan Francis Bacon yang menggambarkan alam hanya sebagai sumber daya, pandangan ini tercermin dan didukung oleh karya Immanuel Kant yang memahami manusia sebagai satu-satunya pembawa nilai intrinsik, sementara hewan dan alam diklasifikasikan dalam istilah instrumental sebagai sarana untuk mencapai tujuan manusia (Riley 2017:68).

White memandang gagasan bahwa alam dirancang semata-mata untuk keuntungan umat manusia merupakan ciri khas yang sangat penting dari kekristenan abad pertengahan. Gagasan tersebut menuntun pada sikap eksploitatif terhadap alam dan ini tidak lepas dari kemenangan kekristenan atas paganism (White 1967:1205). Kekristenan mengajarkan dominasi eksploitatif manusia atas alam dan membebaskan manusia secara spiritual untuk mengeksploitasi alam. Gagasan ini tersebar dengan sikap antianimisme dan memberantas paganisme ketika penyebaran agama kristen berlangsung di abad pertengahan. Hal ini perlu dilakukan karena kepercayaan orang-orang Eropa pra-kristen melihat alam non-manusia memiliki nilai-nilai intrinsik.

Upaya Kekristenan untuk memberantas paganisme dan pandangan animistik meletakkan dasar-dasar etis, psikologis, agama, dan sosial yang nantinya memungkinkan para pemikir, seperti Descartes, untuk memproklamirkan hewan menjadi tidak lebih dari mesin belaka (Riley 2017:69). Pandangan yang berpusat 
pada manusia ini dianggap akan membawa kehancuran karena akan mengarah pada sikap instrumentalis dimana alam digunakan untuk kepentingan manusia semata.

White melihat begitu pentingnya perubahan pandangan dunia. Ia melihat sikap anti animisme yang menyebar seiring dengan masuknya ajaran kekristenan di sebut sebagai revolusi psikis terbesar dalam sejarah (White 1967:1205). Revolusi psikis tersebut mengakibatkan manusia mempunyai lisensi penuh untuk mengeksploitasi alam tanpa peduli nilai-nilai intrinsik dari alam. Jika pemberantasan pemahaman animisme dan paganisme menyebabkan ketidakpedulian dan perilaku eksploitatif pada alam, maka cara memulihkan atau memperlambat krisis ekologis adalah membalikkan pandangan kekristenan yang telah ada.

\section{ALternATIF ETIKA LINGKUNGAN KRISTEN LYNN WHITE}

White berpendapat bahwa tidak perlu ada agama baru yang menggantikan kecenderungan etika antroposentrisme kekristenan, yang diperlukan adalah interpretasi yang radikal untuk membalikkan kecenderungan antroposentris tersebut. White menganjurkan posisi teologis yang disebut demokrasi spiritual semua makhluk Tuhan (spiritual democracy of all God's creatures) dan terkadang menggunakan istilah demokrasi semua makhluk Tuhan (democracy of all God's creatures) di hampir semua karyanya yang diterbitkan tentang agama dan ekologi baik itu di Historical Roots, Christian Impact on Ecology, Snake Nests and Icons, Continuing the Conversation, A Remark from Lynn White, Jr., The Future of Compassion, Commentary on St. Francis of Assisi dan Ecology and Religion (Riley 2014:940-45). Posisi teologis yang dianjurkan White kemudian diharapkan dapat menggantikan interpretasi tulisan Alkitab tentang penguasaan dan penatalayanan ciptaan yang dianggap instrumentalis. Menurutnya, posisi teologis tersebut didukung oleh pandangan St. Fransiskus dari Asisi, Mazmur 96: 11-13 dan Daniel 3: 57-90.²

Mazmur 96:11-12 tersirat alam ciptaan Allah memiliki nilai-nilai intrinsik, seperti yang tertulis: "Biarlah langit bersukacita dan bumi bersorak-sorak, biarlah gemuruh laut serta isinya, biarlah beria-ria padang dan segala yang di atasnya, maka segala pohon di hutan bersorak-sorai." Namun, menurut White, nilai yang tertinggi ditemukan dalam kitab Daniel 3:57-90 yang bertemakan "Song of the Three Children of Israel in the Fiery Furnace". Dalam teks tersebut seluruh ciptaan baik itu

${ }^{2}$ White menyayangkan teks dalam kitab Daniel tersebut tidak menjadi bagian dalam Alkitab protestan. 
malaikat, matahari, bulan dan bintang, hujan, embun, angin dan api, es, es dan salju, malam dan siang hari, kilat dan awan, gunung dan bukit, laut dan sungai, makhluk laut, burung, binatang buas, anak-anak manusia, Israel, para imam Allah, jiwa-jiwa orang benar, orang-orang yang rendah hati semuanya diperintahkan untuk memuji dan mengagungkan Allah selamanya (White 1978:106). Teks tersebut tidak membedakan semua makhluk, sehingga, manusia tidak berada pada posisi dominasi atas ciptaan lainnya, namun, sebagai mitra untuk memuji Allah. Ciptaan Allah lainnya tidak bisa dipandang semata-mata instrumental kehidupan manusia dan manusia bukanlah pusat nilai kehidupan.

Konsep etika penatalayananpun dianggap White tetap bersifat antroposentris sehingga dianggap gagal untuk terlibat dalam pembaharuan psikis secara radikal. Etika penatalayanan hadir di tengah etika dominasi yang eksploitatif, etika tersebut disebut sebagai pemikiran "bijaksana" namun akan memperdalam permasalahan:

"Religious thinkers have been precipitously abandoning the doctrine of Man's Dominion over Nature for that of Man's Trusteeship [i.e. Stewardship] of Nature. This is rational, because no other visible creature seems to be as capable of analysing complex situations and calculating the options as is homo sapiens. Yet it is precisely for this rational reason that this choice will only deepen disaster: it overlooks the fact of sin, which is compounded of inertia, of a nice talent for discovering moral reasons for committing evil deeds, and of self-love both individual and for our species as compared with other creatures. Mankind cannot be trusted to be trustee [e.g. stewards] for the rest of nature." (White 1978:106)

White berpendapat bahwa manusia tidak dapat dipercaya untuk menempatkan kepentingan yang lain (nonmanusia) di atas kepentingannya (manusia) sendiri. Sifat egoisme manusia tersebut tidak terlepas dari dosa asal yang menyelimutinya. Karena hal tersebut, White yakin bahwa mengganti gagasan tentang dominasi dengan etika penatalayanan hanya akan memperburuk masalah ekologis. Hal ini dikarenakan penatalayanan tetap menempatkan manusia di atas makhluk lain dalam hierarki dan ciptaan Allah nonmanusia lainnya tetap dipandang sekadar alat yang digunakan untuk tujuan manusia, oleh karena itu, etika Kristen harus dibersihkan dari semua motivasi yang terlihat "bijaksana" (White 1978:107).

White mengharapkan kekristenan melampaui etika antroposentris, baik itu yang dibingkai dengan kata dominansi ataupun penatalayanan. Sesuai dengan 
diktum Kant, tidak ada orang dapat digunakan sebagai sarana untuk mencapai tujuan orang lain, White ingin etika tersebut juga berlaku pada alam. Alam tidak dapat digunakan sebagai sarana untuk mencapai tujuan manusia, sehingga diperlukan transformasi etika agama untuk memperoleh pemaknaan yang berbeda mengenai keberadaan semua ciptaan.

Etika yang disarankan White adalah manusia dan nonmanusia bersamasama merangkul dalam bagian demokrasi spiritual semua makhluk Tuhan. Orang Kristen perlu memberikan cinta kasih kepada semua ciptaan, baik itu tumbuhan, hewan dan seluruh bagian alam biotik agar manusia dan makhluk lain dapat berkembang bersama (White 1978:109).

Riley menemukan artikel Lynn White yang tidak dipublikasikan dan tidak bertanggal, berjudul Rethinking Science for a Rethought World, tertulis:

"The humane movement is morality at its best because there is nothing prudential about it. It is the expression of an abstract obligation to fellow-creatures without expectation of reward or fear of consequences if one fails in the obligation. After all, actions motivated by such fears or hopes are not moral but merely expedient. Probably as the ecological movement matures, it likewise will become less prudential. Certainly today there is a response to suffering in animals which has no precedent in our culture and which indicates that our notion of the man-nature relationship has been changing more profoundly than most of us have suspected." (Riley 2017:74)

White melihat perlu adanya perubahan yang mendalam dalam gerakan etis yang dilakukan. Dalam tulisan White berjudul Continuing the Conversation kepedulian yang bagi kesejahteraan seluruh "makhluk" tidak hanya bagi yang hidup (tumbuhan dan hewan), namun juga benda-benda mati (White 1973:62-63). Semua "makhluk" tersebut adalah rekan spiritual otonom untuk memuji Allah. Dalam persekutuan seluruh makhluk yang ia bayangkan, semua bagian alam adalah penyembah otonom dalam "demokrasi spiritual" kosmik yang luas, yang disatukan oleh ikatan kekerabatan dan persahabatan (White 1973:61). Ia menuliskan:

"Today, we have the creaturely companionship not only of the flowering tree that so enraptured Schweitzer, or the earthworm that he removed from the perils of the sidewalk: we can sense our comradeship with a glacier, a subatomic particle or a spiral nebula. Man must join the club of the creatures. They may help to save us from ourselves." (White 1978:107) 
White menggunakan term "makhluk" (ciptaan) dalam bentuk yang inklusif, dikarenakan term tersebut tidak hanya menunjukkan makhluk hidup tapi seluruh entitas tidak bernyawa, konsep tersebut ada dalam berbagai tulisan White seperti "Christian and Nature", "The Future of Compassion" dan "Commentary on St. Francis of Assisi” (Moore 2014; White 1982:17-19).

Jadi, sebagai orang Kristen, perintah mengasihi Allah dan sesama harus diperluas kepada ciptaan Allah nonmanusia. Cinta kasih dan kepedulian semua makhluk ciptaan Allah dan kepada Allah seperti dua sisi mata uang yang tidak terpisahkan. Etika tersebut didasari atas semua ciptaan Allah memiliki nilai otonom tidak didasari atas relasi hirearkis manusia dan alam, seperti yang ditulis dalam "The Future of Compassion":

"From Christian compassion we must defend the continued existence of our fellow animal, plant, insect and marine species, as well as the integrity of land scapes, seascapes and airscapes that are periled by human activity, whether or not the se in any way affect buman existence. We must do this because of our belief that they are all creatures of God, and not from expediency. We must extend compassion to rattlesnakes and not just to koala bears." (White 1978:108-9)

Manusia harus menghormati semua makhluk, dan semua makhlukpun harus menunjukkan "cosmic manners" yang sama kepada manusia sebagai timbal balik (White 1978:107). White memberikan contoh anjing hutan dan belalang yang menjadi sasaran manusia untuk dimusnahkan karena dianggap merugikan manusia. Sekalipun makhluk tersebut merugikan manusia, tidak berarti manusia dapat memusnahkan mereka, dengan demikian relasinya menjadi tidak seimbang dan antroposentris (White 1978:107). Baik manusia maupun makhluk lain memiliki hak atas sumber daya yang mereka butuhkan untuk hidup dan mereka tidak boleh melanggar kapasitas satu sama lain untuk berkembang. Meskipun manusia dirugikan dengan keberadaan para binatang tersebut, White merasa manusia bertindak terlalu jauh ketika berusaha untuk memusnahkan belalang dan makhluk lain secara massal.

\section{TELAAH KRITIS ETIKA LINGKUNGAN LYNN WHITE}

Pengaruh etika lingkungan White sangat terlihat dalam ensiklik Paus Fransiskus dalam Laudato Si: On Care for Our Common Home (2015). Dalam 
dokumen itu, Paus Fransiskus memuji peran St. Fransiskus Asisi dalam membantu umat menuju ekologi integral. Setiap makhluk ikut memuji Tuhan dan setiap makhluk adalah saudari yang bersatu dengan ikatan kasih sayang (paragraf 11) (Pope Francis 2015).

Menurut Paus Fransiskus keyakinan seperti itu tidak dapat diremehkan sebagai romantisme yang naif, sebab berdampak atas pilihan-pilihan yang menentukan untuk perilaku kita (Pope Francis 2015). Jika memandang alam dan lingkungan tanpa keterbukaan untuk kagum dan heran, jika kita tidak lagi berbicara dengan bahasa persaudaraan dan keindahan dalam hubungan kita dengan dunia, kita akan bersikap seperti tuan, konsumen, pengisap sumber daya, hingga tidak mampu menetapkan batas-batas kebutuhan yang mendesak, sebaliknya, jika kita merasa intim bersatu dengan semua yang ada, maka kesahajaan dan kepedulian akan timbul secara spontan (Pope Francis 2015).

"Gema" etika lingkungan White terlihat dalam proklamasi ini. Menurut Paus Fransiskus, hewan dan makhluk lain juga menyembah Tuhan dengan caranya sendiri, dan semua makhluk berharga bagi Allah dan memiliki nilai dalam dirinya sendiri, Paus Fransiskus menggambarkan menggambarkan setiap makhluk perlu ada dalam persekutuan universal (paragraf 76) dan dalam paragraf 221, menggambarkan ini dalam istilah persaudaraan mulia dengan seluruh ciptaan. Meskipun tidak menggunakan bahasa "demokrasi spiritual", keserasian dalam makna sangat kuat dengan etika lingkungan White yang telah disarankan beberapa dekade sebelumnya (Pope Francis 2015).

Etika lingkungan White melintasi zamannya, namun, tidak jarang pula pemikirannya yang seringkali dijadikan referensi tidak dilihat secara lengkap. White seringkali dikenal sebatas tesis mengenai akar kerusakan lingkungan yang melihat kontribusi besar agama Kristen dalam pengrusakan lingkungan. Namun, White tidak sebatas mengemukakan tesis tersebut, dia juga memberikan alternatif etika lingkungan dan ia juga mengkritisi beberapa alternatif etika yang terlihat "bijaksana".

Dalam artikel Ken Gnananakan, seorang pecinta lingkungan dan teolog Injili dari India, yang berjudul Creation, Christians and Environmental Stewardship, artikel tersebut diawali dengan keresahan terhadap tesis Lynn White mengenai akar kerusakan lingkungan pada tahun 1967. Ken Gnanakan mengkritisi Lynn White yang yang memahami secara harafiah penggunaan kata kabas dan radah dalam Kejadian 1:28, 
"The problem to critics like White, obviously, is with the words used. The Hebrew word kabas and radah are said to be much harsher than the English translations. Kabas means 'to tread down', to bring into bondage' or even 'to rape' while radah means 'to trample' or 'to press' and therefore to rule or dominate. The Hebrew words, like most of our Asian languages, have a rich array of meanings and need not necessarily be taken literally. As we look closer at the implications, we will get nearer to the fuller understanding as was intended in the command." (Gnanakan 2015:128)

Selain itu, alternatif biosentrisme yang ditawarkan Lynn White, menurut Ken Gnanakan, tidak dapat dibenarkan secara Alkitabiah. Dan Iapun menawarkan etika penatalayanan sebagai alternatif, padahal, Etika penatalayanan tersebut ternyata sudah dikritisi oleh Lynn White sebagai etika yang terlihat "bijaksana", namun, menurut White, tetap mengasumsikan relasi hirearkis manusia dan ciptaan Allah lainnya dan tetap tidak memperbaiki keadaan.

Jika anggapan Lynn White benar bahwa pandangan dunia yang melihat relasi hirearkis antara manusia dan makhluk lainnya akan berdampak eksplotatif dalam perilaku manusia, maka kekristenan, akan sulit menemukan alternatif etika yang berdampak bagi pelestarian lingkungan. Seperti yang dianjurkan Ken Gnanakan, yaitu etika penatalayanan, etika tersebut merupakan etika Alkitabiah yang lebih mudah ditemukan dibandingkan etika demokrasi semua makhluk Tuhan milik Lynn White.

Para teolog Kristen seperti Ken Gnanakan dan lainnya, seringkali mengkritisi Lynn White, namun terjebak dengan cara berpikir Lynn White dalam memandang peran agama:

"Paradoxically, although many ecotheologians argued vociferously against White, they could use his thesis to reinforce the view that environmen-talism was at bottom a religious and ethical movement. Like White, they believed that religious values were the most effective antidote." (Whitney 2005:1736)

Cara berpikir yang demikian akan memandang nilai-nilai dan ide-ide agama merupakan penggerak perjalanan sejarah budaya dan berdampak besar dalam kenyataan material yang sedang terjadi. Sebaliknya, para teolog dan ahli etika dapat memulai kritik terhadap metodologi Lynn White agar tidak terjebak dalam cara berpikir idealis. Whitney, ahli sejarah sains dan teknologi, 
mempertanyakan pandangan White, apakah ia menunjukkan bahwa agama adalah penyebab perkembangan teknologi atau perkembangan teknologi (yang bergerak juga karena faktor ekonomi dan politik) dibingkai dalam term agama (Whitney 2005:1736). Jika mengikuti pandangan yang kedua, maka etika lingkungan perlu berbalik, dari menilai dan mengubah nilai-nilai dan ide-ide kosmologi agama, menjadi mengasah keterlibatan kritis dalam realitas ekonomi dan politik, menggeser tugas etis dari mengubah pandangan kosmologi menjadi mengubah praktik sosial. Hal ini disebabkan penghancuran ekologis juga berkaitan dengan masalah politik dan ekonomi dan membutuhkan solusi yang berdampak secara struktural dan institusional (Magdoff and Foster 2018). Sedangkan Lynn White terlihat berada pada posisi pertama.

Masalah lingkungan dalam dua dekade terakhir secara konsisten berada di puncak perhatian, survei di Amerika (negara dengan mayoritas beragama Kristen) menunjukkan bahwa empat dari lima orang sebagai pecinta lingkungan, namun kesadaran ini tidak sejalan dengan dampak yang dihasilkan (Peterson 2007:45). Dari 80 persen orang Amerika dapat diidentifikasi sebagai pencinta lingkungan, kurang dari 20 persen yang secara teratur berpartisipasi dalam kegiatan yang bertanggung jawab terhadap lingkungan seperti daur ulang, mengurangi konsumsi pribadi, mendukung bisnis hijau, menghilangkan limbah dan polusi hingga terlibat dalam aktivisme lingkungan (Peterson 2007:45). Bahkan praktik "hijau" mengalami stagnasi atau bahkan menurun sejak permulaan gerakan lingkungan massal pada tahun 1970-an, di sisi lainnya, perilaku yang merusak secara ekologis telah meningkat secara eksponensial pada periode yang sama, jika diukur dalam hal konsumsi bahan bakar fosil, konsumsi sumber daya mentah, memperluas ukuran rumah, populasi yang meningkat hingga pilihan politik (Peterson 2007:45).

Kesenjangan antara gagasan dan praktik juga hadir dalam keagamaan, yang diidentifikasi oleh Lynn White sebagai arena penting dalam perjuangan untuk ekologis berkelanjutan. Banyak pemimpin agama telah menyatakan bahwa perusakan ekologis adalah krisis spiritual, sehingga dibentuk pula pemahaman dan penilaian baru tentang relasi dengan lingkungan. Hal ini terlihat dengan berbagai macam deklarasi dan konsensus yang diharapkan dapat menciptakan kehidupan ekologis yang berkelanjutan dalam beberapa dekade terakhir. Namun, dengan menjadikan permasalahan lingkungan sebagai prioritas, menemukan dan mengembangkan nilai-nilai kepedulian lingkungan, semua hal tersebut tidak serta-merta menghadirkan transformasi signifikan dalam praktik. 
Buddhisme dan Taoisme sering disebut contoh sistem pemikiran ramah lingkungan, yang menekankan saling ketergantungan manusia dan lingkungan ekologis. Namun, masyarakat Asia yang didominasi oleh tradisi Buddha atau Tao, antara lain, memiliki sejarah deforestasi yang terdokumentasi dengan baik, pertanian yang tidak berkelanjutan, kekejaman terhadap hewan, dan banyak lagi lainnya (Peterson 2007:53). Bahkan budaya penduduk asli Amerika, yang pandangan dunianya dipandang oleh banyak filsuf lingkungan sangat "hijau", telah berpartisipasi dalam perburuan berlebihan dan merusak alam (Peterson 2007:53).

Permasalahan yang hadir pada saat ini bukan saja interpretasi terhadap nilai-nilai dan ide-ide yang dipercayai dalam masyarakat, namun juga apa yang dapat dilakukan di tengah situasi kerusakan lingkungan. Bisa dikatakan sudah cukup banyak para ahli menafsirkan dunia, dan sekarang harus melangkah dengan pertanyaan bagaimana cara mengubahnya.

White sendiri tidak memberikan pola tindakan tertentu untuk mengatasi kerusakan lingkungan. Dalam pandangan White, etika Kristen lebih berpusat pada sikap bukan tindakan (White 1978:100). White menjelaskan bahwa perubahan dalam tindakan tanpa perubahan nilai-nilai dapat menjadi bencana, "we shall not cope with our ecologic crisis until scores of millions of us learn to understand more clearly what our real values are" (White 1973:56). Oleh karena itu, tulisan-tulisan White sangat sedikit menjelaskan mengenai program aksi yang dilakukan. Adapun beberapa saran yang diberikan adalah: mendorong ilmuwan dan insinyur untuk menemukan dan mengembangkan cara-cara baru dan cara-cara yang lebih berhati-hati untuk menggunakan sumber daya alam yang tidak tergantikan dan menemukan metode daur ulang sampah hingga cara mencegah polusi (White 1978:109). Ia juga menyarankan manusia untuk transisi gaya hidup menjadi non-konsumtif (White 1978:109). Semuanya bersifat individual tidak menyentuh persoalan struktural.

Kesenjangan ini seharusnya patut menjadi perhatian para ahli etika pasca White. Kritik dan etika lingkungan White telah membuat para sarjana menghabiskan waktu untuk membongkar teka-teki nilai-nilai intrinsik dan instrumental, ide-ide ramah ekologis dalam Alkitab, dsb. Semua perhatian tersebut penting, namun, tugas yang juga tidak kalah penting dari para ahli etika lingkungan adalah mencari bagaimana agar orang hidup sesuai dengan ide-ide yang telah dimiliki dan praktik seperti apa yang dapat dilakukan agar "tepat sasaran" di tengas konteks kerusakan lingkungan saat ini.

Nilai-nilai hidup dapat memperbaiki teori dan membentuk tradisi yang baik, hal tersebut adalah proyek penting dan perlu, namun hal tersebut tidak 
berarti dengan menafsirkan realitas melalui cara berbeda maka dengan sendirinya mengubah realitas. Seperti kaum hegelian muda yang dikritik Marx dalam Ideologi Jerman, "... that they are in no way combating the real existing world when they are merely combating the phrases of this world" (Marx 1845). Penulis tidak berarti beranggapan bahwa tidak ada hubungan antara mengubah praktik dan mengubah nilai-nilai juga ide-ide. Disini terlihat perlunya interaksi timbal balik yang kompleks di antara keduanya dan etika sosial yang dihasilkan berdampak pada pembaharuan struktural dan institusional.

\section{PENUTUP}

Lynn White dikenal dengan tesis mengenai akar kerusakan lingkungan, namun, yang seringkali terlewatkan adalah mengenai etika demokrasi bagi semua makhluk yang dianjurkan Lynn White. White mencoba membangun ekosentrisme Kristen dan menyarankannya sebagai pandangan dunia yang berguna untuk mengatasi masalah kerusakan lingkungan. "Gema” pemikiran Whitepun terdengar sampai beberapa dekade setelahnya.

White melihat pentingnya perubahan nilai-nilai dan ide-ide yang dimiliki manusia jika ingin mengubah dunia. Etika yang dianjurkan White kurang memberikan porsi kepada tindakan praktis dan merumuskan solusi yang berdampak langsung pada perubahan. White meyakini bahwa perubahan dalam etika harus berasal dari perubahan internal dalam penekanan intelektual dan keyakinan manusia, bukan sebaliknya (White 1970:46-64).

Tesis White mengenai akar kerusakan lingkungan banyak direspons oleh para sarjana, namun, etika lingkungan White sering diabaikan. Beberapa alternatif etika yang bermuculan seringkali sudah dijawab maupun digugurkan melalui etika lingkungan Lynn White. Namun yang pasti, seringkali para sarjana yang merespons Lynn White mengikuti metode berpikir idealis, dengan menganggap peran yang sangat penting dalam perubahan ide-ide dan nilai-nilai untuk mempengaruhi perubahan dunia. Faktor-faktor material, seperti pergeseran dalam praktik ekonomi dan perubahan dalam sains dan teknologi, yang juga mempengaruhi perilaku kurang mendapatkan perhatian.

Masalah kerusakan lingkungan yang semakin parah, mendesak timbulnya kebutuhan akan etika adaptif yang terbuka untuk menemukan solusi yang tepat sasaran dan fleksibel dalam mengatasi masalah yang kompleks serta terus berkembang. Kerusakan lingkungan yang terjadi saat ini tidak sekadar persoalan nilai-nilai individu manusia, namun juga persoalan struktural. Perlu adanya 
interaksi timbal balik antara pembaharuan nilai-nilai dan praktik-praktik kehidupan untuk menemukan etika sosial yang berdampak pula pada pembaharuan struktural dan institusional.

\section{DAFTAR PUSTAKA}

Callicott, John Baird. 1999. Beyond the Land Ethic : More Essays in Environmental Philosophy. New York: State University of New York Press.

Gnanakan, Ken. 2015. "Creation, Christians and Environmental Stewardship." Journal of Social, Technological and Environmental Science 4(3).

Jenkins, Willis. 2009. “After Lynn White: Religious Ethics and Environmental Problems.” Joumal of Religious Ethics. doi: 10.1111/j.1467-9795.2009.00387.x.

Magdoff, Fred, and John Bellamy Foster. 2018. Lingkungan Hidup Dan Kapitalisme: Sebuah Pengantar. Yogyakarta: Marjin Kiri.

Marfa, Aris. 2016. Pengantar Etika Lingkungan Dan Kearifan Lokal. Yogyakarta: Gadjah Mada University Press.

Marx, Karl. 1845. “The German Ideology: Part I.” Marxist.Org. Retrieved October 10, 2019 (https://www.marxists.org/archive/marx/works/1845/germanideology/ch01a.htm).

Moore, Stephen D. 2014. Divinanimality: Animal Theory, Creaturely Theology.

Nur, Said. 2019. "Mencairnya Es Greenland Sebabkan Kenaikan Permukaan Air Laut.” Tirto. Retrieved January 10, 2020 (https://tirto.id/dbdh).

Peterson, Anna. 2007. "Talking the Walk: A Practice-Based Environmental Ethics as Grounds for Hope." in EcoSpirit: Religions and Philosophies for the Earth, edited by L. Kearns and C. Keller. New York: Fordham University Press.

Pope Francis. 2015. ENCYCLICAL LETTER LAUDATO SI'. The Holy Father Francis On Care For Our Common Home.

Riley, Matthew T. 2014. “THE DEMOCRATIC ROOTS OF OUR ECOLOGIC CRISIS: LYNN WHITE, BIODEMOCRACY, AND THE EARTH CHARTER.” Zygon® 49(4):938-48. doi: 10.1111/zygo.12139.

Riley, Matthew T. 2017. “The Wicked Problem of Climate Change.” Worldviews 21(1):61-86. doi: 10.1163/15685357-02101005. 
White, Lynn. 1967. “The Historical Roots of Our Ecologic Crisis.” Science. doi: 10.1126/science.155.3767.1203.

White, Lynn. 1970. "History and Horseshoe Nails." in The Historian's Workshop, edited by L. P. Curtis. New York: Alfred A. Knopf.

White, Lynn. 1973. "Continuing the Conversation.” Pp. 55-64 in Western Man and Environmental Ethics: Attitudes Toward Nature and Technology, edited by I. Barbour. London: Addison-Wesley Publishing Company.

White, Lynn. 1978. “The Future of Compassion.” The Ecumenical Review 30(2):99109. doi: 10.1111/j.1758-6623.1978.tb03508.x.

White, Lynn. 1982. "Commentary on St. Francis of Assisi.” Bohemian Club Library Notes.

Whitney, Elspeth. 2005. "White, Lynn (1907-1987) - Thesis Of.” in Encyclopedia of Religion and Nature, edited by Taylor and J. Kaplan. New York: Thoemmes Continuum. 